\title{
Respiratory metabolism of Idotea baltbica (Crustacea, Isopoda) in relation to environmental variables, acclimation processes and moulting
}

\author{
H.-P. BulnheIM \\ Biologische Anstalt Helgoland (Zentrale); \\ Hamburg 50, Federal Republic of Germany
}

\begin{abstract}
KURZFASSUNG: Der respiratorische Stoffwechsel von Idotea balthica (Crustacea, Isopoda) in Beziehung zu Umweltfaktoren, Anpassungsvorgängen und zum Häutungsgeschehen. Der Atmungsstoffwechsel der euryhalinen Meeresassel Idotea baltbica (Pallas) wurde in Abhängigkeit von der Körpergröße, der Temperatur und dem Salzgehalt untersucht. Die auf elektrochemischem Weg durchgeführten Messungen des Sauerstoff̈bedarfs ergaben eine nahezu gleichmäßige Erhöhung der Stoffwechselintensität mit zunehmender Temperatur. Gegenüber dem Ruheumsatz steigr der Aktivitätsstoffwechsel bei allen getesteten Temperaturen $\left(5^{\circ}, 10^{\circ}\right.$, $15^{\circ}, 20^{\circ} \mathrm{C}$ ) ungefähr um das 3- bis 4 fache. Die größenbezogenen Stoffwechselrelationen zeigen eine deutliche Abhängigkeit von der Salinität. Der zeitliche Verlauf der Anpassungsvorgänge nach einem Temperatur- und Salinitätsstreß wurde bis zum Erreichen eines neuen, gleichbleibenden Stoffwechselniveaus verfolgt. Die Adaptation nach einem plötzlichen Temperaturwechsel (Uberführung von $15^{\circ}$ in $5^{\circ} \mathrm{C}$ und von $5^{\circ}$ in $15^{\circ} \mathrm{C}$ ) ist innerhalb weniger Stunden vollzogen. Ein abrupter Salinitätswechsel von 30 in $10 \%$ hat einen wesentlich längeren und mit einem erheblichen Stoffwechselanstieg verknüptten Anpassungsvorgang zur Folge als ein Salzgehaltssprung in umgekehrte Richtung. Ferner wurden die Anderungen des Sauerstoffbedarfs während der Häutung, die sich in zwei räumlich und zeitlich getrennten Abschnitten vollzieht, untersucht. Der Sauerstoffverbrauch adulter Individuen ist iiber einen Zeitraum von ca. 40-80 Stunden (bei $15^{\circ} \mathrm{C}$ ) erhöht und weist während des Abwurfs des alten Exoskeletts einen zweigipfligen Anstieg auf, der etwa das Dreifache der Normalwerte erreicht. Verschiedene physiologische Aspekte werden unter Einbeziehung ökologischer Gesichtspunkte, die sich insbesondere auf das vorwiegend sublitorale Vorkommen von $I$. balthica beziehen, erörtert.
\end{abstract}

\section{INTRODUCTION}

The representatives of the isopod genus Idotea inhabit mainly marine littoral zones. Along the German coasts six different Idotea species have been recorded (Gruner 1965); of these, Idotea balthica represents one of the most common forms which may be found locally in high abundance within sublittoral algal belts and eelgrass-meadows. Its significant population densities convey to I. baltbica considerable importance in the energy flow through littoral ecosystems. On the one hand, it participates in the utilization of the primary production in the sea and, on the other hand, 
it serves as food for several other marine animals, especially for fishes. Although the members of the genus Idotea are potentially omnivorous scavengers, seaweeds, eelgrass and floating vegetable debris provide the main food source in their particular habitat (NAYLOR 1955). This is also reflected by the observation that, to some extent, several Idotea species are closely associated with certain benthonic algae.

Various aspects of the ecology and general biology have been thoroughly studied in several Idotea species. However, as pointed out by Jones (1974), contributions to the physiology of this genus are still limited. Among the physiological subjects studied some investigations have been undertaken on activity patterns (JANSSON \& KäLLANDER 1968, HøRLYCK 1973a), heat resistance (FURCH 1972), osmoregulatory capacities (ToDD 1963, HørLyck 1973b) as well as metabolism and energy exchange (Fox \& Simmonds 1933, Storcovica \& Rosca 1958, von Oertzen 1965, Strelinikova 1971, KhMeleva 1973, Shapunov 1973, Jones 1974).

The experiments reported here contribute to the environmental physiology of Idotea balthica and complement previous pertinent studies. They were undertaken to test the influences of temperature and salinity on oxygen uptake as related to body size. In addition, the effects of environmental stress, in particular the compensatory reactions following changes of ambient temperature and salinity have been recorded in relation to the time courses of acclimation and the magnitudes of the physiological adjustments. Finally, some data are presented on alterations of metabolic rates during the moulting process.

\section{MATERIALS AND METHODS}

Specimens of Idotea baltbica (PALLAS) were collected in spring and summer in near-shore waters of the Lübeck Bay (Baltic Sea). The salinity in this area averages $15 \%$. The isopods were sorted from algae and leaves of Zostera marina, transferred to the laboratory and maintained in aerated aquaria supplied with a bottom filter. Usually, they were kept at constant temperatures $\left(5^{\circ}, 10^{\circ}, 15^{\circ}, 20^{\circ} \mathrm{C}\right)$ for several weeks until use for experiments. In general, brackish water of $10 \% \mathrm{~S}$ served as culture medium. During summer time, under natural light-dark cycles, the isopods reproduced in the laboratory (at $15^{\circ} \mathrm{C}$ ), but mostly failed to do so during other seasons. Enteromorpha sp., pieces of Mytilus edulis flesh and commercial fish food ("Tetramin") comprised the diet offered.

Idotea balthica is subdivided into several subspecies. On the coasts of western and northern Europe four allopatric subspecies (or geographical races) have been recorded, which are both morphologically and ecologically separated from each other. On the basis of the descriptions given by TinturIER-Hamelin (1963) the specimens found in the Lübeck Bay were assigned to Idotea baltbica baltbica.

The respiratory rates were measured by a flow-through polarographic technique providing continuous $p \mathrm{O}_{2}$ determinations. The experimental set-up used has been described in detail in a publication dealing with investigations on the metabolism of Gammarus species (BulNHEIM 1972).

The whole experimental system consisted of a respirometer and a recording unit. 
A pump (Unita II $b$, Braun, Melsungen) continuously forced a constant flow of airsaturated water through the glass respirometer. The animal chamber inserted in this system was adjusted to the size of the test organisms. In combination with a magnetic stirrer, a Clark-type electrode determined dissolved oxygen in the aqueous solution. The electrode employed consisted of a platinum cathode, protected from the sample being measured by thin membranes of cellophane and Teflon, and a silver-silver chloride reference electrode. $0.5 \mathrm{~m} \mathrm{KCl}$ solution served as an electrolytic agent. The electrode operated in conjunction with an oxygen analyser (Eschweiler \& $\mathrm{Co}$, Kiel) and a "Servogor" recorder (Metrawatt, Nürnberg). The readout was in millimetres oxygen partial tension. Detailed references to calibrations and calculations are given in the afore-mentioned paper.

In order to reduce the activity of the individuals examined, a piece of gauze which meets the thigmotactic behaviour of the idoteids was inserted in the respiration chamber. Measurements of single specimens were conducted in the respirometer submerged in a temperature-controlled water bath at $5^{\circ}, 10^{\circ}, 15^{\circ}$, and $20^{\circ} \mathrm{C} \pm 0.1^{\circ} \mathrm{C}$ in media of $10 \%$ and $30 \% \mathrm{~S}$, respectively. Prior to experimental use the test animals were starved for one day. They remained in the respiration chamber until constant oxygen-uptake rates were obtained. In general, the values recorded during the first two hours of the $p \mathrm{O}_{2}$ determinations were discarded. Before and after each run, and additionally during long-term recordings, control measurements (without test animals) were performed. The flow of water through the respirometer was adjusted such that the isopods generally consumed less than $10 \%$ of the available oxygen.

\section{RESULTS}

\section{Oxygen consumption and size}

In poikilotherms, the dependence of oxygen consumption on body size has been verified by many investigators (cf. HEMMINGSEN 1960). In most cases this relationship is not linear; rather, the oxygen-uptake rates represent an exponential function of body weight. Therefore, an adequate characterization of the specific metabolic levels of a given poikilothermic animal species requires determinations of respiratory rates as a function of size.

The mathematical expression of metabolism per unit time is given by the allometric formula: $y=a \cdot x^{b}$, where $y=\mathrm{O}_{2}$ consumption, $x=$ weight, $a$ and $b=$ constants. The regression coefficient $b$ indicates the slope of the logarithmic plot of oxygen consumption versus body weight and the parameter $a$ expresses the intercept on the $\mathrm{Y}$-axis. This plot gives a straight line with a positive slope; a negative slope results, when weight-specific respiration is calculated, whereby the equation assumes the form $y / x=a \cdot x^{b-1}$.

In several isopod species, the effects of various environmental factors on metabolism have been examined. However, relatively few publications are devoted to their influences on the relationships between rates of oxygen uptake and body size. In Idotea balthica, first the effects of various temperature levels $-5^{\circ}, 10^{\circ}, 15^{\circ}$, and $20^{\circ} \mathrm{C}$ 
- on respiration were studied. The temperature range selected corresponded fairly well to the thermal regime which the idoteids normally encounter in their habitat.

In general, the test animals were pre-exposed to each experimental temperature
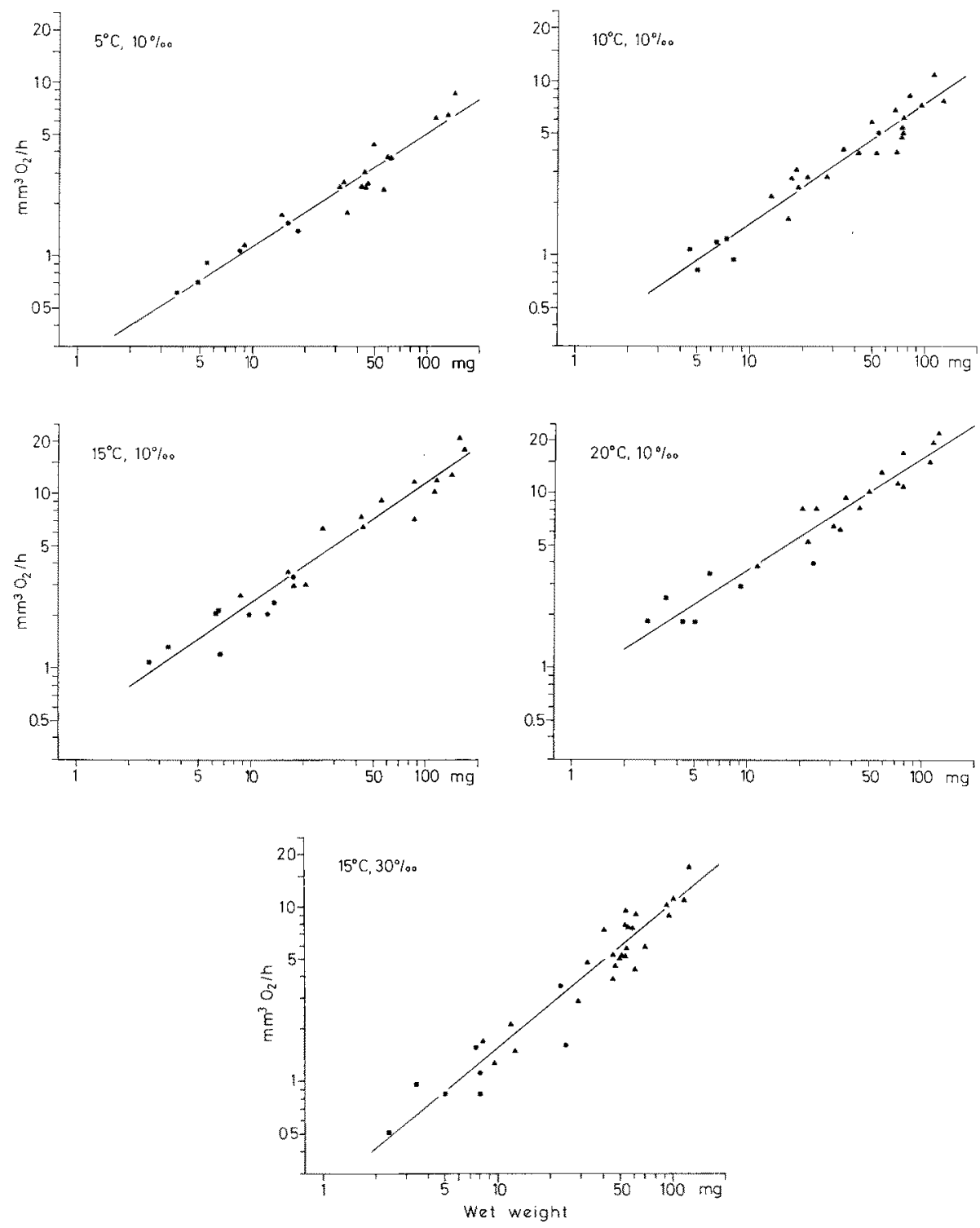

Fig. 1: Idotea balthica. Relationships between oxygen uptake and size at four different temperatures and two salinities. Symbols: $\mathbf{0}$ juveniles, $\bullet$ females, $\boldsymbol{A}$ males. The respective values computed for determination of levels and slopes of the regression lines (parameters $a$ and $b$ as well as their standard errors) are listed in Table 1 
for several weeks, at least for a minimum of 5 days. In addition to the experiments conducted at a salinity of $10 \%$, oxygen determinations were also performed at $30 \%$ and $15^{\circ} \mathrm{C}$. The results obtained from these investigations were intended to serve as a basis for the studies on acclimation processes to be described later.

Figure 1 illustrates the relationships between oxygen consumption and body size as related to temperature and salinity; Table 1 summarizes the corresponding data calculated which are supplied with further parameters necessary for statistical analysis. As can be seen from this figure, the values measured scatter to some extent about the

Table 1

Idotea baltbica. Data calculated for characterizing oxygen consumption $\left(\mathrm{mm}^{3} \mathrm{O} / \mathrm{g} / \mathrm{g} / \mathrm{h}\right)$ as a function of body size in relation to temperature $\left({ }^{\circ} \mathrm{C}\right.$ ) and salinity $(\% 0) . a=$ intercept of the regression line on the $\mathrm{Y}$-axis indicating oxygen uptake per unit weight ( $1 \mathrm{~g}$ wet weight), $b=$ regression coefficient, $s_{y} \cdot x=$ standard error of the $y$ values for a given value of $x, r=$ coefficient of correlation, $\mathrm{n}=$ number of specimens measured

\begin{tabular}{|ccccccc|}
\hline${ }^{\circ} \mathrm{C}$ & $\%$ \% & $a$ & $b$ & $\mathrm{~s}_{y} \cdot x$ & $r$ & $\mathrm{n}$ \\
\hline 5 & 10 & $22.54 \pm 1.15$ & $0.64 \pm 0.04$ & 0.080 & 0.97 & 21 \\
10 & 10 & $35.22 \pm 1.15$ & $0.68 \pm 0.04$ & 0.087 & 0.96 & 27 \\
15 & 10 & $56.80 \pm 1.15$ & $0.69 \pm 0.04$ & 0.095 & 0.97 & 24 \\
20 & 10 & $68.18 \pm 1.17$ & $0.63 \pm 0.04$ & 0.098 & 0.95 & 23 \\
15 & 30 & $67.52 \pm 1.16$ & $0.81 \pm 0.04$ & 0.105 & 0.96 & 34 \\
\hline
\end{tabular}

regression lines reflecting individual variation. Most of the test animals chosen were males; only few, non-reproducing females were used. Since no differences between the sexes appeared to occur, the respiratory data for males and females were pooled for regression analysis.

The high levels of the coefficients of correlation calculated clearly document the dependence of respiratory rates on body size. The different thermal regimes exert a marked effect on the rates of standard metabolism indicating an almost continuous rise with increasing temperature. From the data presented, rate-temperature curves as well as $\mathrm{Q}_{10}$ values may be calculated. Such procedure has been omitted, since slight differences of these values between various size groups are expected to result as a consequence of the diverse regression coefficients obtained. The latter show significant differences in the slopes of the log weight - log oxygen uptake regression lines, when the rates are compared between 30 and $10 \%(p<0.05)$. In $10 \%$ metabolic rates are higher than in 30\%; however, the regression lines converge at the end of the weight range tested. In contrast to the rather high level of the regression coefficient obtained at $30 \%$, the $b$ values calculated from the measurements in media of $10 \%$ range approximately between 0.6 and 0.7 ; thus they reflect rather close proportionality of metabolism to body-surface area which is indicated by an exponent of 0.67 .

The slopes of the regression lines obtained at $10 \%$ and the four temperature regimes examined were compared with one another for testing significances. The statistical treatment of the data by employing analysis of covariance did not reveal significant differences $(p>0.2)$ between the various regression coefficients.

In respiratory studies it is importance to distinguish between standard and active 
metabolic rates. On the basis of the characteristic patterns obtained during the continuous $p \mathrm{O}_{2}$ monitoring and including visual inspections of the isopods examined in the respirometer, it was possible to differentiate between active and standard metabolism and to evaluate the level of activity to some degree. Between the two rates corresponding to maximal and minimal activity, various levels of routine rates may be distinguished. During the experiments conducted, activity effects due to locomotion were largely excluded by the small sizes of the respiration chambers used and the substratum provided to which the idoteids were attached. Due to the quiscent behaviour of most specimens tested, maximum values could be measured in only a few cases. Accordingly, regression coefficients relating to active metabolism have not been calculated. However, some tentative values on the scope for activity, i.e. the difference between standard and active rates of metabolism (FRY 1957), could be obtained, although it is not certain whether the respiratory data recorded of active specimens represent maximal rates which might occur under natural conditions. Some recordings have shown that, during periods of extreme excitement, the activity rates measured exceed standard rates by approximately four times at $10^{\circ}$ and $15^{\circ} \mathrm{C}$. Values nearly three times the standard rates have been obtained, on the other hand, at $5^{\circ}$ and $20^{\circ} \mathrm{C}$, but there is some evidence that they are too low. This approach of estimating activity metabolism only refers to adult specimens; it cannot be excluded that some sizedependent differences exist in this respect. This aspect should be examined more precisely by employing adequate methods to measure oxygen uptake and activity simultaneously.

\section{Metabolic responses following environmental stress}

\section{Temperature stress}

Many poikilotherms are known to be able to compensate for changes in temperature conditions which they are exposed to (for review, see PREcht et al. 1973). Although several investigations have been performed testing the capacity for temperature acclimation in crustaceans, only few studies, however, have taken into account the time course of this compensatory adjustment.

The following experiments were carried out in order to study the time required for transition from one acclimation state to another. Adult males of Idotea baltbica, acclimated under laboratory conditions to two different temperature regimes, $5^{\circ}$ and $15^{\circ} \mathrm{C}$, respectively, were subjected to sudden changes of temperature. Figures 2 and 3 illustrate the results of these experiments. A sudden transfer of warm acclimated animals from $15^{\circ}$ to $5^{\circ} \mathrm{C}$ led to a new metabolic steady state within ca. 3 hours. The oxygen-uptake rates measured thereafter roughly corresponded to the rates of longterm acclimated isopods to $5^{\circ} \mathrm{C}$ (cf. Fig. 1). The high rates initially recorded may have been partially caused by disturbances which the test animals had experienced due to the transfer into the respiration chamber.

A similar response was found in the second set of experiments, the abrupt exposure of cold acclimated individuals from $5^{\circ}$ to $15^{\circ} \mathrm{C}$. On the average, the time 
course until attaining a new metabolic level at the altered temperature lasted approximately 15 hours. After the thermal stress a slight decrease of respiration rates occurred indicating that for a while at the elevated temperature the test animals were in a

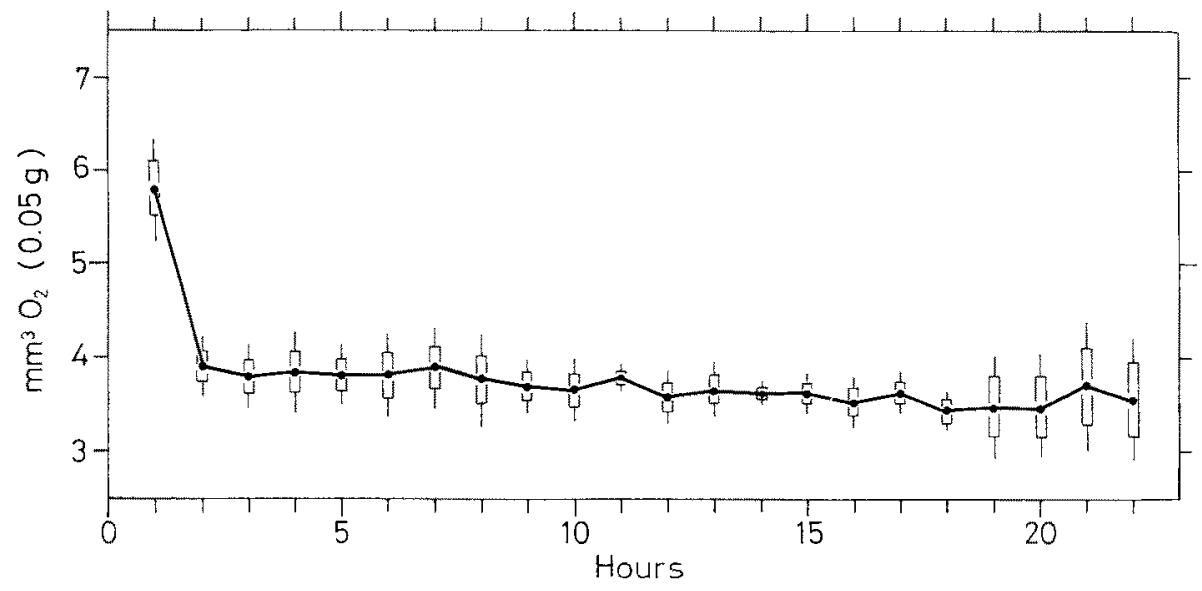

Fig. 2: Idotea balthica. Time course of acclimation in adult $\hat{\delta} \hat{\delta}$ (corrected to $0.05 \mathrm{~g}$ body weight) following sudden transfer from $15^{\circ}$ to $5^{\circ} \mathrm{C}(\mathrm{n}=4)$. Vertical lines: standard deviation; vertical bars: standard error of the mean

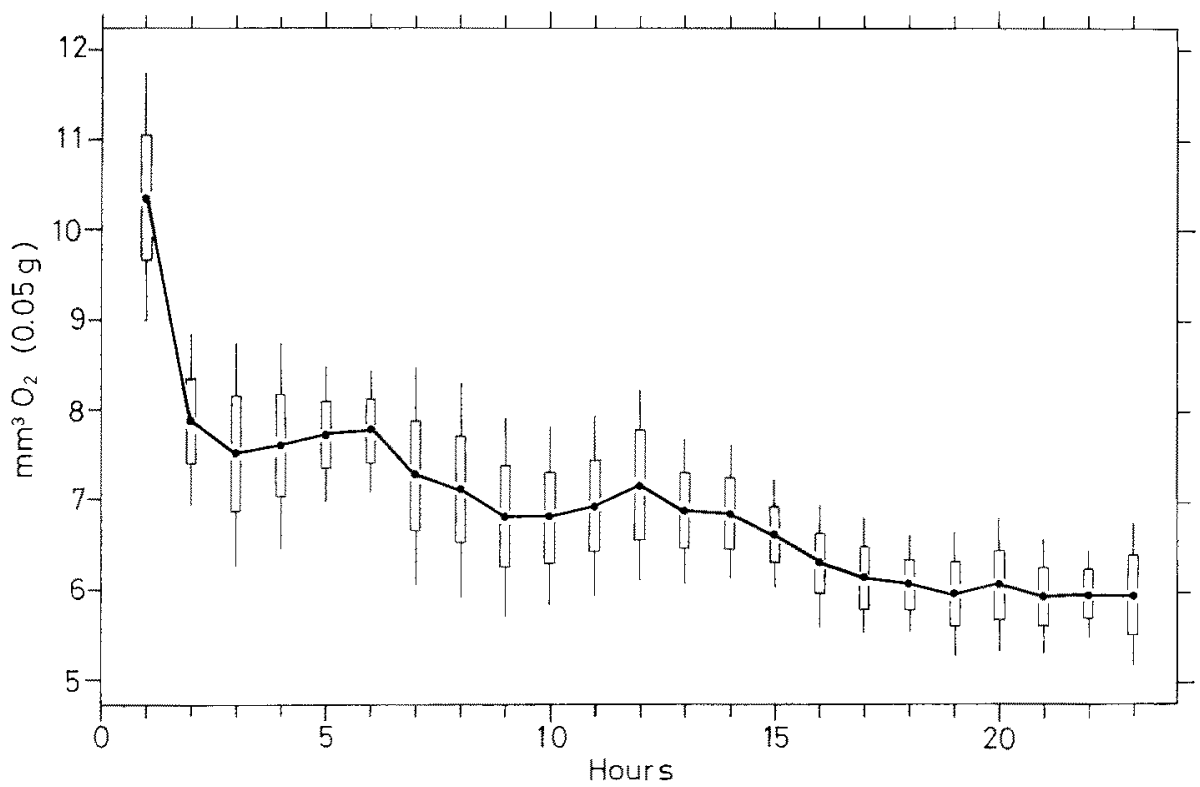

Fig. 3: Idotea balthica. Time course of acclimation in adult $\delta \hat{\delta}$ (corrected to $0.05 \mathrm{~g}$ body weight) following sudden transfer from $5^{\circ}$ to $15^{\circ} \mathrm{C}(\mathrm{n}=4)$. Vertical lines; standard deviation; vertical bars: standard error of the mean 
somewhat excited state which slowed down after they had been undisturbed for several hours in the respirometer. This also became apparent in further experiments with specimens of different size. In conclusion, thermal acclimation has no significant effect on the rate-temperature relations of respiratory metabolism in 1 . baltbica.

\section{Salinity stress}

Idotea baltbica tolerates a wide salinity range. SEGERSTRÅLE (1947) noted that it occurs in the northern Baltic Sea in salinities as low as $3.5 \%$ and SYwuLA (1964) reported a minimum mean salinity tolerance of about $4.25 \%$. Inhabiting brackish as well as sea water, I. baltbica is distributed on both European and American coasts. Generally, it prefers localities with clear and continuously renewed water, but avoids environments associated with strong salinity fluctuations. The tolerance to a wide salinity range is based on well-developed osmoregulatory capacities. As demonstrated by Horlyck (1973b), I. baltbica exhibits a hyperosmotic regulation which is in accordance with the mode of osmoregulation in other euryhaline Idotea species investigated.

The experiments conducted follow a design that was applied in studies on adaptation to changes of environmental salinity in several euryhaline Gammarus species (BulnheIm 1972). After long-term acclimation to salinity of $10 \%$, individuals of $I$. balthica were suddenly exposed to a salinity level of $30 \%$ and vice versa. During these studies oxygen-consumption rates of adult individuals were first measured for at least 7 hours at the external concentration to which they were acclimated for a long period of time. Thereafter, they were subjected to a sudden rise or fall of ambient salinity, without modifying the conditions of oxygen measurement. The responses following osmotic stress were continuously monitored until new steady levels were obtained. The relative oxygen-uptake rates expressed in Figures 4 and 5 refer to the percentages of increase or decrease in respiration rates compared with the metabolic levels which occurred before the salinity was altered.

An abrupt change from 10 to $30 \%$ led to some decrease of the oxygen consumption (Fig. 4). After an initial overshoot the metabolic reaction settled down to a new stabilized rate within 4 to 6 hours following the salinity change. Thereafter, the oxygen uptake was reduced by about $10 \%$ in relation to the preceding metabolic activity. Since during the next few hours no further alterations occurred - except for some minor fluctuations - the period of compensatory adjustment is considered to be rather short. It should be pointed out that this finding of reduced $\mathrm{O}_{2}$ uptake in $30 \%$ is in accordance with the above presented results on oxygen-consumption rates versus body weight as influenced by salinity (cf. Fig. 1).

In contrast to the transfer from a more dilute to a more concentrated medium, a quite different response could be ascertained when the opposite experiment was performed. A sudden salinity fall from 30 to $10 \%$ also induced an initial overshoot which was associated with a rather long period of maintaining an increased oxygen uptake (Fig. 5). For about 20 hours following the osmotic stress, oxygen-consumption rates were elevated on an average of $40 \%$. Thereafter, during the next 10 hours, the 
metabolic rates gradually decreased until attaining a new steady state, which was slightly higher than it was before exposure to the salinity stress. Thus, the whole process of physiological compensation associated with the salinity change from 30 to $10 \%$ required ca. 30 hours. Compared with the results of the first set of the salinity experiments and, in addition, taking into consideration observations of the test animals, there is good reason to suspect that the raised oxygen-uptake rates can be attributed to the compensatory reaction rather than indicating a high level of spontaneous activity.

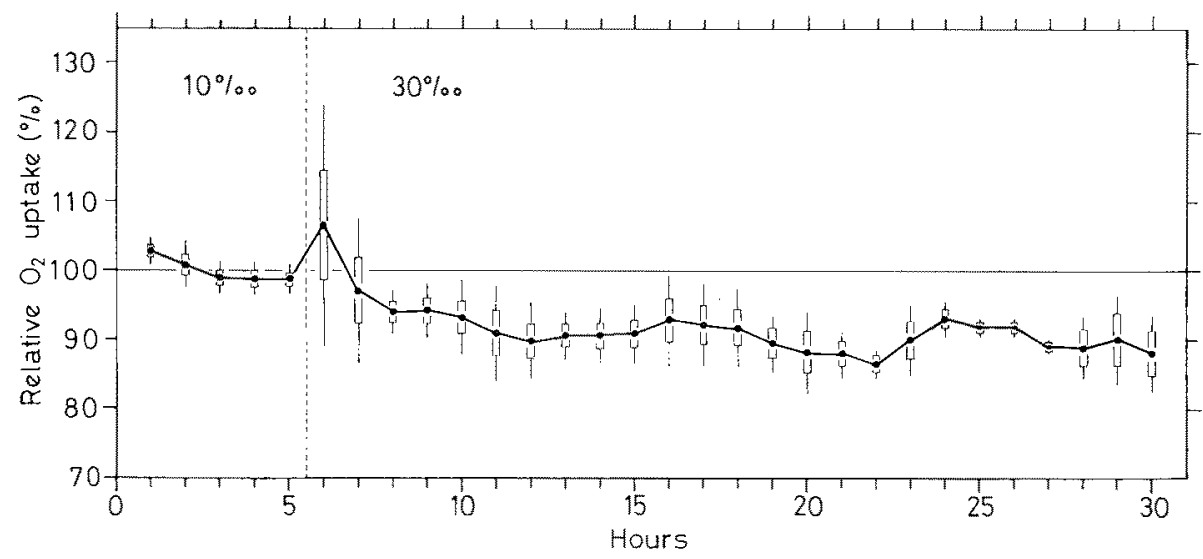

Fig. 4: Idotea balthica. Time course of salinity acclimation $(\hat{O} \hat{O}$, ca. $0.05 \mathrm{~g}$ ) following abrupt change from 10 to $30 \%$ S at $15^{\circ} \mathrm{C}(\mathrm{n}=5)$. Vertical lines: standard deviation; vertical bars: standard error of the mean

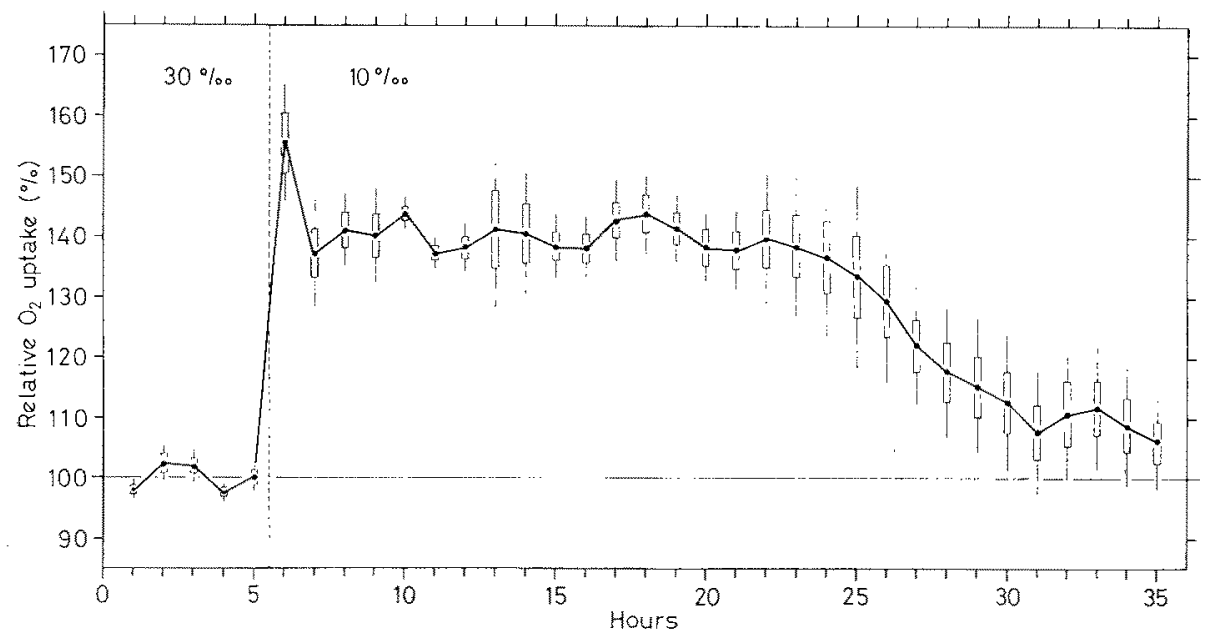

Fig. 5: Idotea baltbica. Time course of salinity acclimation ( $\hat{\delta} \hat{\partial}, \mathrm{ca} .0 .05 \mathrm{~g}$ ) following abrupt change from 30 to $10 \% \mathrm{~S}$ at $15^{\circ} \mathrm{C}(\mathrm{n}=5)$. Vertical lines: standard deviation; vertical bars: standard error of the mean 


\section{Metabolic changes during moulting}

All crustaceans grow through periodic shedding of the exoskeleton. The process of moulting is associated with various morphological, physiological and biochemical changes which have received special attention in decapods (Passano 1960). In isopods, however, little is known on metabolic alterations related to moulting and on the role of endogeneous and exogeneous factors controlling this process. Thus far only WIESER (1965) has reported on changes of respiratory rates during moulting in the woodlouse porcellio scaber.

The representatives of the order Isopoda are characterized by a bipartite exuviation. During the first phase of moulting the integument is split between the fourth and fifth thoracic segment providing in the first instance the withdrawal of the old cuticle from the last thoracic segments and the abdomen. Temporally separated from this ecdysis posterioris, at a later date exuviation of the anterior body part, the ecdysis anterioris, is accomplished. In reproducing females, during the interphase between both moultings, copulation takes place. The duration of this phase is dependent on temperature and size. Observations made in adult specimens of Idotea balthica revealed an interphase period of 15 hours ( $9,13 \mathrm{~mm}$ body length, $15^{\circ} \mathrm{C}$ ), 17 hours $\left(\hat{O}, 15 \mathrm{~mm}\right.$ body length, $15^{\circ} \mathrm{C}$ ), and 10 hours $\left(\hat{O}, 17 \mathrm{~mm}\right.$ body length, $20^{\circ} \mathrm{C}$ ). Taken all together, the respiratory alterations during moulting were measured in six individuals; however, in three of them these studies could not be accomplished throughout the whole process of ecdysis.

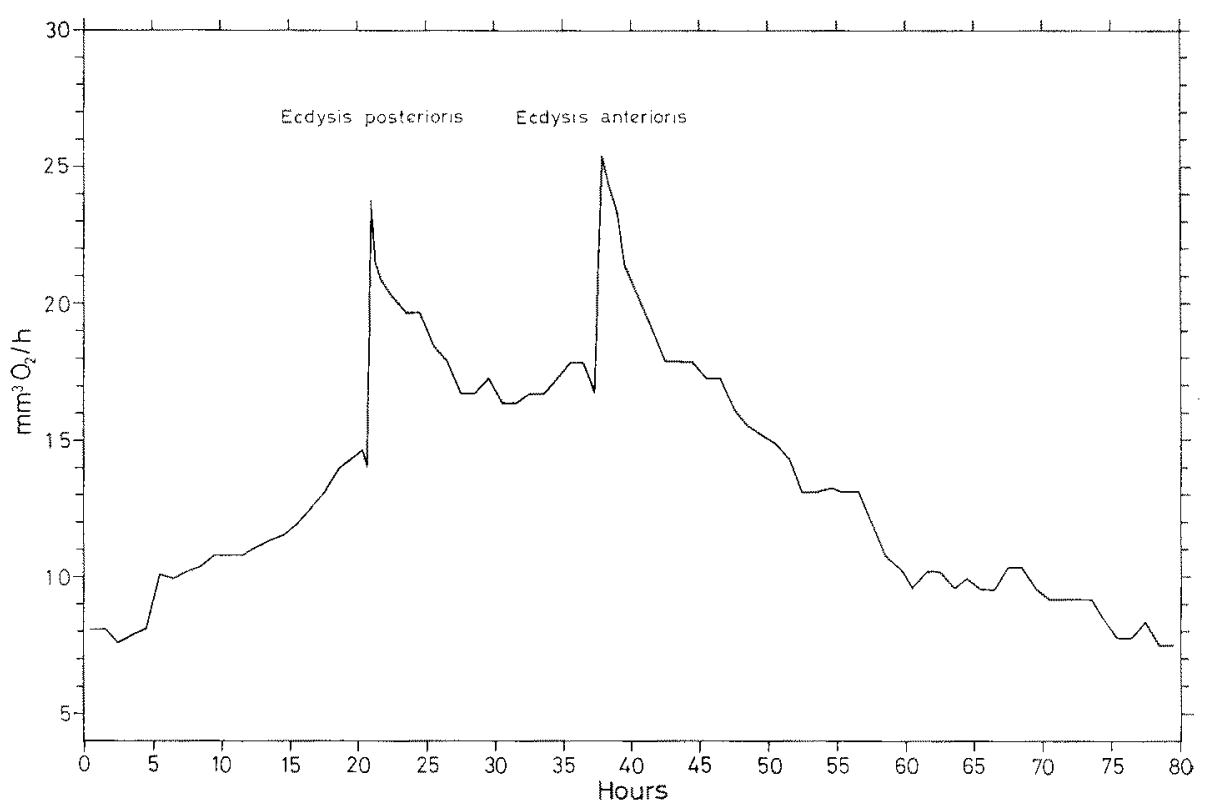

Fig. 6: Idotea balthica. Respiratory alterations associated with moulting ( $\left.\hat{0}, 0.054 \mathrm{~g}, 15^{\circ} \mathrm{C}, 10 \%\right)$ 
The continuous monitoring of oxygen-consumption rates during moulting has clearly shown that the changes of metabolic rates recorded correspond to the two exuviation phases (Fig. 6). At the end of the premoult stage, about 8-15 hours prior to the posterior ecdysis (at $15^{\circ} \mathrm{C}$ ), a gradual increase in the rate of oxygen uptake could be noted; sometimes it was intensified by periods of activity bursts. When the withdrawal from the posterior part of the old exoskeleton was effected, a sharp rise in oxygen consumption appeared. Thereafter, a decline of the oxygen demand occurred, although elevated rates were maintained at an almost constant or slightly decreasing level. The interphase is terminated by a second sharp peak reflecting the moult of the anterior body part. Finally, a gradual decline of oxygen-consumption rates ensued until normal values, corresponding more or less to premoult levels, were reached. This period required approximately the same time as the corresponding process of premoult. As related to adult individuals ( $>10 \mathrm{~mm}$ body length) and a temperature of $15^{\circ} \mathrm{C}$, the whole phase of increased metabolic requirements during moulting was shown to comprise a period of ca. 40 to 80 hours. It is dependent on temperature and body size: decreasing temperature and increasing size cause a temporal prolongation of the whole process.

On average, the two peaks of which the second was found to be generally somewhat higher than the first one exceeded standard rates about three times, whereas in the interphase the rise of metabolic rates was about twice the standard values. The sharp peaks during exuviation appeared to be caused by short bursts of intense activity in the course of which, within a few minutes, the act of shedding was accomplished. The high oxygen demand during the interphase, on the other hand, was not related to such excitatory behaviour, since the test animals generally spent most of their time in an inactive state. Hence, it appears to be a consequence of the absorption of water and other physiological processes associated with moulting.

According to the cyclic structural changes of the skeleton and other characteristics, the intervals between the moults may be subdivided into several intermoult stages. The criteria established by DRACH (1939) for decapods have been applied to isopods in a slightly modified form (STEVENSON 1961, WIESER 1965). In the course of these studies it became obvious that - except for the late premoult and early postmoult stages - resting metabolism measured in intervals during an individual intermoult cycle did not reveal further significant variations.

In this connection, it appears to be of some interest to include some data on the moulting frequency in Idotea baltbica. Although only few data have been gathered, evidence was provided that in males subsequent intermoult stages recur with progressively longer duration. It was found, that the intermoult cycle of males at a body length of $10 \mathrm{~mm}$ averages 2-3 weeks and that of $20 \mathrm{~mm}$ sized males averages 4 weeks maintained at $15^{\circ} \mathrm{C}$ and $10 \%$. On the other hand, in females a scattering of the moulting frequency was observed; moreover, it could not yet be clarified if there exist differences between females in reproductive or resting stages, respectively.

\section{DISCUSSION}

Many factors are known to affect the rate of respiration in poikilothermic animals. They involve body size, activity, temperature, oxygen concentration, nutritive 
conditions and other variables. Some of these exogenous and endogenous factors have been shown to be interdependent and hence, it may be difficult to assess their relative importance on oxygen-uptake rates.

The above results on the relationships between oxygen consumption and body size in Idotea baltbica, as related to temperature and salinity, demonstrate such environmental influences. The different levels and slopes of the regression lines indicate the extent to which external conditions can affect metabolism. Variations in the regression coefficients due to environmental factors such as temperature and salinity are well documented in crustaceans (Dehnel 1960, McFartand \& Pickens 1965, BulnheIM 1972) and other invertebrates. Similar to Idotea balthica, relatively higher regression coefficients were also found in several euryhaline Gammarus species, when a comparison was made between oxygen-uptake rates in more concentrated and more dilute external media. The $b$ values obtained in this study correspond to most of the regression coefficients calculated for other crustaceans including isopods (Wolvekamp \& Waterman 1960); generally they are between 0.67 and 1 , indicating a range between surface-related and weight-related respiration.

The results reported demonstrate that, within the range tested, neither resting nor active metabolism of $I$. baltbica remains thermally insensitive. This is in contrast to the findings obtained from various intertidal invertebrates including crustaceans whose active and standard metabolic rates may be affected by temperature differently (NEWELL 1969, 1973). In most instances, the active rate of respiration has been shown to be markedly temperature-dependent, whilst the standard rate of quiescent animals reveals a relatively low temperature coefficient. As discussed by NEwELL (1973), there appears to be an ecological pattern in the occurrence of temperature-insensitive respiratory metabolism which is evidently confined to intertidal animals. Such homeostasis is of adaptive value to them, since they are frequently subjected to wide and rapid temperature fluctuations. In contrast, subtidal organisms generally do not display temperature independence of metabolism. This conclusion has thus been confirmed by the present investigations on the subtidally occurring $I$. balthica. Furthermore, it was shown in the terrestrial isopod Porcellio scaber that standard as well as "excited" and active rates of metabolism are similarly affected by and increase with rising temperature (NEwELL et al. 1974).

Another aspect to be discussed concerns salinity adaptation which involves several physiological and ecological implications. It is a well-documented fact that various euryhaline invertebrates respond to reduced salinity levels by an increase of respiratory rates. This observation does not only apply to Idotea balthica but also to Hemigrapsus oregonensis (DeHnel 1960), Carcinus maenas (SCHLIEPER 1929, Lucu et al. 1973), Balanus balanoides (Barnes et al. 1963), Gammarus species (Bulnhetm 1972) and other crustaceans. Moreover, in several marine and brackish-water invertebrates, different patterns of metabolic responses may occur after exposure to salinity alterations; these have been reviewed and classified by KINNE (1971). Several explanations have been put forward regarding the physiological mechanisms that might be responsible for the alterations of the respiratory rates following a decrease or increase of the ambient salinity level. This problem has been critically discussed by POTTS \& PARRY 
(1964); however, an understanding of the different types and magnitudes of the metabolic responses established is still lacking.

The metabolic alterations following a salinity stress are closely associated with changes of osmotic and ionic concentrations of extracellular and intracellular body fluids. Assessing the literature available, only few papers contain information on the time courses of salinity acclimation as related to respiratory rates, osmoconcentrations and other processes involved.

The periods of acclimation in crustaceans, which had been exposed to osmotic stress, were studied, for example, in some decapods (Gross 1957, Siebers et al. 1972, LuCU et al. 1973), gammarids (BuLNHEIM 1972) and in the isopod Cyathura polita (SEgal \& Burbanck 1963). It is obvious that the time course of such compensatory adjustments until attaining a new steady state of performance depends on the animal species examined, the magnitude as well as the direction of salinity change, and other factors. General conclusions cannot as yet be drawn.

With regard to the temporal relationships of the different functional responses involved, it is of interest to compare the present data on the alterations of respiratory rates with the results published by HørLYCK (1973b) on the time courses of osmotic adaptation in $I$. bathica and related species. When specimens of $I$. baltbica were transferred from a salinity of 24,5 to $6 \%$ the freezing-point depression of the haemolymph fell from $1.42^{\circ}$ to about $1.0^{\circ}$ after one hour (at $10^{\circ} \mathrm{C}$ ); during the next 20 hours it decreased gradually to reach a new steady state with a mean value of $\triangle^{\circ} \mathrm{C}$ $=0.8$. When the opposite experiment was undertaken comprising a change from 7 to $25 \%$ the freezing-point depression rose from $0.71^{\circ}$ to about $1.28^{\circ}$ within one hour; during the following 5 hours a new mean steady-state value $\left(\triangle^{\circ} \mathrm{C}=1.38\right)$ was approached.

It is interesting to note that these time courses of acclimation are very similar to those obtained from the above-reported experiments on the changes of respiratory metabolism (Figs. 4 and 5), although the levels of the salinity alterations are somewhat different (from 10 to $30 \%$ and vice versa) when compared with the experimental conditions of HøRLYCK's study.

Summing up, these results demonstrate that changes from more dilute to more concentrated external media induce less extensive alterations in rates of oxygen uptake and lead to a shorter acclimation period than transfers in the opposite direction. In this regard a parallelism to some euryhaline Gammarus species, particularly to Gammarus locusta must be stressed. As studied by alterations of oxygen uptake in this amphipod, an abrupt transfer from 10 to $30 \%$ leads to a new steady state of metabolic rates within 3-5 hours, whereas acclimation following a sudden transfer from 30 to $10 \%$ takes 30 or more hours (BuLNHEIM 1972). The sudden exposure to the dilute medium which is also associated with an elevated hyperosmotic regulation in $G$. locusta causes a significant temporary increase of respiratory rates. In contrast to this, in $G$. duebeni the corresponding acclimation period takes about 3 hours and is not accompanied by marked respiratory changes. This difference must be related to the species-specific environmental requirements of the amphipods concerned. $G$. duebeni occurs in habitats, especially in the supralittoral zone, characterized by extreme fluctuations of salinity levels and other ecological factors. Like Idotea baltbica, 
Gammarus locusta is preferentially distributed in subtidal localities, but avoids estuaries and other adverse environments tolerated by $G$. duebeni. From this interspecific physiological comparison the patterns of distribution of the species under consideration become more conspicuous. The enhanced oxygen-uptake rates reflect a considerable degree of energy expenditure due to a rapid salinity decline; this suggests that neither I. baltbica nor G. locusta are suited to live in environments where strong salinity fluctuations are likely to occur. On the other hand, the wide occurrence of both species in the Baltic Sea demonstrates that they are able to exist in rather low salinities provided that the concentration of the ambient medium remains fairly constant. In any case, the acclimatory responses obtained indicate that $I$. baltbica is better adapted to tolerate rapid temperature changes than sudden salinity alterations.

Before considering the metabolic requirements of moulting, the data of previously published papers pertaining to the metabolism of Idotea species should be briefly discussed. It is often difficult to compare published values of oxygen-uptake rates because of differences in the techniques employed, temperatures applied, weight units used, and physiological conditions of the test animals chosen. Hence, the few data reported on oxygen consumption of Idotea baltbica, I. neglecta, $l$. chelipes (I. viridis), I. emarginata, and I. ochotensis (Fox \& Simmonds 1933, Storcovici \& Rosca 1958, v. Oertzen 1965, Strelnikova 1971, Jones 1974) cannot be compared adequately with the values presented in this study. Above all, these publications do not refer to rate-size relationships, except for the studies of STRELNIKova (1971) and KHMELEva (1973).

The respiratory rates measured and compared by Jones (1974) in Idotea neglecta, I. emarginata and $I$. chelipes reveal only slight differences and are similar to those of other marine peracarid crustaceans. In $I$. chelipes, in contrast to the other two Idotea species, an increase of the oxygen demand was noted after exposure to reduced salinity levels.

The alterations in respiratory metabolism displayed during moulting by Idotea baltbica are similar to those recorded in the woodlouse Porcellio scaber (WIESER 1965). At ecdysis, the latter species also shows two peaks of increased metabolic rates which correspond to the exuviations of the exoskeleton being cast in two parts.

In several other crustaceans elevated metabolic requirements have also been measured prior to, or at, ecdysis. This applies to decapods (Scudamore 1947, Frost et al. 1951, Burss 1953, Scheer \& Scheer 1954, Roberts 1957, Heinemann 1964) euphausiids (PARANJAPE 1967) and amphipods (Bulnherm 1972). In various Gammarus species, for example, oxygen consumption increases the standard metabolic rates by 2.2 to 3.9 times during moulting. On the other hand, no such alterations have been detected in the cirripede Balanus improvisus variatio denticulata (Costrow \& Bookнout 1958), whereas a low increase, amounting to approximately $32 \%$, was ascertained in moulting specimens of Balanus balanoides (BARNES \& BARNEs 1963). The data published thus far indicate that in crustaceans oxygen uptake mostly exceeds standard metabolic rates by $2-4$ times in the course of this process. The rather long duration of the bipartite moulting in isopods, accompanied by an extended period of elevated oxygen demand implies that exuviations are particularly hazardous events in 
their life. This accounts for the observation that, besides failure to complete moulting, unfavourable environmental conditions frequently lead to deaths when approaching or passing ecdysis.

\section{SUMMARY}

1. The oxygen uptake of the euryhaline isopod Idotea baltbica (PALlas), obtained from the Baltic Sea, was determined by means of flow-through polarography. The rates of respiration were studied in relation to body size, temperature and salinity. Measurements conducted at $5^{\circ}, 10^{\circ}, 15^{\circ}$ and $20^{\circ} \mathrm{C}$ in $10 \%$ salinity revealed an almost continuous increase of metabolic rates with rising temperatures. The regression coefficients, calculated for size-dependent respiration, range from about 0.7 to 0.6. Compared with these data, a significantly higher regression coefficient was obtained from determinations made at $15^{\circ} \mathrm{C}$ and $30 \%$. The rates of active metabolism in adult individuals were shown to exceed standard metabolism by approximately 3 to 4 times at all temperatures tested.

2. The compensatory responses following thermal and salinity stress have been recorded in relation to the time courses of acclimation and the magnitudes of the physiological adjustments. Sudden alterations of temperature lead to new steady states of metabolic rates within 3 hours following a change from $15^{\circ}$ to $5^{\circ} \mathrm{C}$ and approximately within 15 hours following a transfer from $5^{\circ}$ to $15^{\circ} \mathrm{C}$. At $15^{\circ} \mathrm{C}$, an abrupt salinity change from 10 to $30 \%$ and vice versa requires a transition period between successive acclimation states of 6 hours $(10$ to $30 \%$ ) and about 30 hours (30 to $10 \%$ ), respectively. The transfer from the dilute to the more concentrated medium is accompanied by slightly reduced oxygen-uptake rates, whereas the transfer in the opposite direction leads to a marked temporary increase of respiration.

3. The time course and intensity of metabolic changes during moulting were also examined. The exuviations of the posterior and anterior body parts occur temporally separated and are reflected by two peaks of increased oxygen uptake, amounting to approximately three times the standard rates. In the interphase between the successive exuviations an elevated respiratory level is maintained. In adult specimens, the whole phase of increased metabolic requirements during moulting comprises a period from 40 up to 80 hours at $15^{\circ} \mathrm{C}$.

4. The metabolic requirements and acclimatory responses of Idotea balthica are considered in relation to its subtidal habitat and compared with compensatory reactions occurring in some intertidal and supratidal invertebrates. Further physiological and ecological implications are discussed.

Acknowledgements. I am indebted to Miss M. Mühlenkamp for technical assistance and to $\mathrm{Mr}$. J. MARSCHALL for preparing the figures.

\section{LITERATURE CITED}

Barnes, H. \& Barnes, M., 1963. The relation of water uptake and oxygen consumption of the body tissues to the molting cycle in Balanus balanoides (L.). Crustaceana 6, 62-68. 
- - \& Finlayson, D. M., 1963. The seasonal changes in body weight, biochemical composition, and oxygen uptake of two common boreo-arctic cirripedes, Balanus balanoides (L.) and B. halanus (L.) DA CosTA. J. mar. biol. Ass. U.K. 43, 185-211.

Buss, D. E., 1953. Endocrine control of metabolism in the land crab, Gecarcinus lateralis (FRÉMINVILLE). I. Differences in the respiratory metabolism of sinus glandless and eyestalkless crabs. Biol. Bull. mar biol. Lab., Woods Hole 104, 275-296.

BuxNHEIM, H.-P., 1972. Vergleichende Untersuchungen zur Atmungsphysiologie eurybaliner Gammariden unter besonderer Berücksichtigung der Salzgehaltsanpassung. Helgoländer wiss. Meeresunters. 23, 485-534.

Costrow, J. D., JR. \& Воокноuт, C. G., 1958. Molting and respiration in Balanus improvisus var. denticulata Broch. Physiol. Zoöl. 31, 271-280.

DEHNel, P. A., 1960. Effect of temperature and salinity on the oxygen consumption of two intertidal crabs. Biol. Bull. mar. biol. Lab., Woods Hole 118, 215-249.

Drach, P., 1939. Mue et cycle d'intermue chez les Crustacés Décapodes. Annls Inst. océanogr., Monaco 19, 103-392.

Fox, H. M. \& Simmonds, B. G., 1933. Metabolic rates of aquatic arthropods from different habitats. J. exp. Biol. 10, 67-74.

$F_{R X}, F . E . J ., 1957$. The aquatic respiration of fish. In: The physiology of fishes. Ed. by M. E. Brown. Acad. Press, New York 1, 1-63.

Furch, K., 1972. Der Einfluß einer Vorbehandlung mit konstanten und wechselnden Temperaturen auf die Hitzeresistenz von Gammartus salinus und Idotea balthica. Mar. Biol. 15, $12-34$.

Gross, W. J., 1957. An analysis of response to osmotic stress in selected decapod Crustacea. Biol. Bull. mar. biol. Lab., Woods Hole 112, 43-62.

Gruner, H.-E., 1965. Krebstiere oder Crustacea. V. Isopoda. Tierwelt Dtl. 51 (1), 1-149.

Heinemann, F., 1964. Der Gewebestoff wechsel einheimischer Dekapoden und seine Bedeutung für ihre Biologie und Okologie. Zool. Jb. (Abt. allg. Zool. Physiol. Tiere) 71, 89-116.

HeMmingsen, A. M., 1960. Energy metabolism as related to body size and respiration surfaces, and its evolution. Rep. Steno meml. Hosp. 9 (2), 1-110.

Horrlyck, V., 1973a. Seasonal and diel variation in the rhythmicity of Idotea baltica (Pallas) and Idotea granulosa RATHKE. Ophelia 12, 117-127.

- 1973b. The osmoregulatory ability in three species of the genus Idotea (Isopoda, Crustacea). Ophelia 12, 129-140.

Jansson, B.-O. \& Källander, C., 1968. On the diurnal activity of some littoral peracarid crustaceans in the Baltic Sea. J. exp. mar. Biol. Ecol. 2, 24-36.

JONES, M. B., 1974. Survival and oxygen consumption in various salinities of three species of Idotea (Crustacea, Isopoda) from different habitats. Comp. Biochem. Physiol, 48 A, 501 to 506 .

Khmeleva, N. N., 1973. Energy metabolism of Idotea baltica basteri (Aud.). (In Russian.) In: Energy metabolism of aquatic animals. The Academy of Science of the USSR, Publ. House "Nauka", Moscow, 5-27.

Kinne, O., 1971. Salinity: Animals - Invertebrates. In: Marine Ecology. Ed. by O. KinNe. Wiley - Interscience, London 1 (2), 821-995.

Lucu, Č., Siebers, D. \& Sperling, K.-R., 1973. Comparison of osmoregulation between Adriatic and North sea Carcinus. Mar. Biol. 22, 85-95.

MCFarland, W. N. \& Pickens, P. E., 1965. The effects of season, temperature and salinity on standard and active oxygen consumption of the grass shrimp, Palaemonetes vulgaris (SAY). Can. J. Zool. 43, 571-585.

NAYroR, E., 1955. The diet and feeding mechanism of Idotea. J. mar. biol. Ass. U.K. 34, $347-355$.

Newell, R. C., 1969. Effect of fluctuations in temperature on the metabolism of intertidal invertebrates. Am. Zool. 9, 293-307.

- 1973. Factors affecting the respiration of intertidal invertebrates. Am. Zool. 13, 513-528.

-, WrEser, W. \& PYE, V. I., 1974. Factors affecting oxygen consumption in the woodlouse Porcellio scaber LATR. Oecologia 16, 31-51. 
Oertzen, J.-A. von, 1965. Stoffwechselaktivitätsmessungen (Sauerstoffverbrauch) an Invertebraten der Fucuszone aus der mittleren Ostsee. Zool. Anz. 175, 166-173.

Paranjape, M. A., 1967. Molting and respiration of euphausiids. J. Fish. Res. Bd Can. 24, 1229-1240.

Passano, L. M., 1960. Molting and its control. In: Physiology of Crustacea. Ed. by T. H. Waterman. Acad. Press, New York 1, 473-536.

PotTs, W. T. W. \& Parry, G., 1964. Osmotic and ionic regulation in animals. Pergamon Press, Oxford, 423 pp.

Precht, H., Christophersen, J., Hensel, H. \& Larcher, W., 1973. Temperature and life. Springer, Heidelberg, $779 \mathrm{pp}$.

Roberts, J., 1957. Thermal acclimation of metabolism in the crab Pachygrapsus crassipes RANDALl. I. The influence of body size, starvation and moulting. Physiol. Zoöl. 30, 232-242.

Scheer, B. T. \& Scheer, M. A. R., 1954: The hormonal control of metabolism in crustaceans. VIII. Oxygen consumption in Leander serratus. Pubbl. Staz. zool. Napoli 25, 419-426.

Schlmeper, C., 1929. Ober die Einwirkung niederer Salzkonzentrationen auf marine Organismen. Z. vergl. Physiol. 9, 478-514.

Scudamore, H. H., 1947. The influence of the sinus glands upon molting and associated changes in the crayfish. Physiol. Zoöl. 20, 187-208.

Segal, E. \& Burbanck, W. D., 1963. Effects of salinity and temperature on osmoregulation in two latitudinally separated populations of an estuarine isopod, Cyathura polita (STMmson). Physiol. Zoöl. 36, 250-263.

Segerstråle, S. G., 1944. Uber die Verbreitung der Idotea-Arten im baltischen Meeresgebiet Finnlands. Commentat. biol. $9(6), 1-6$.

Sxwula, T., 1964. A study on the taxonomy, ecology and geographical distribution of species of the genus Idotea FABricrus (Isopoda, Crustacea) in Polish Baltic. II. Ecological and zoogeographical part. Bull. Soc. Sci. Litt Poznan 4(D), 173-200.

Shapunov, V. M., 1973. Calorie value of Black Sea Idotea baltica basteri (Aud.). (In Russian.) In: Energy metabolism of aquatic animals. The Academy of Science of the USSR, Publ. House "Nauka", Moscow 62-73.

Siebers, D., Lucu, C., Sperling, K.-R. \& Eberlern, K., 1972. Kinetics of osmoregulation in the crab Carcinus maenas. Mar. Biol. 17, 291-303.

Stevenson, J. R., 1961. Polyphenol oxydase in the integumental glands in relation to the moulting cycle of the isopod crustacean Armadillidium vulgare. Biol. Bull, mar. biol. Lab., Woods Hole, 121, 554-560.

Storcovici, F. \& Rosca, D. I., 1958. Comportarea la variatii de salinitate. XLIV. Variatia consumului de oxigen la unif crustacei in cursul pricesului de edilibrare osmotică cu mediul exterior. Studii Cerc. Biol. Cluj 9, 103-112.

Strelnikova, V. M., 1971. Metabolism intensity in Isopoda crustaceans, Idotea ochotensis Brandt (Idoteidae) and Cymodoce acuta Rich. (Sphaeromatidae). (In Russian.) Gidrobiol. Zh. 7, 101-105.

Tinturier-Hameln, E., 1963. Polychromatisme et détermination génétique du sexe chez l'espèce polytypique Idotea baltbica (Pallas) (Isopode valvifère). Cah. Biol. mar. 4, 473-591.

Topd, M. E., 1963. Osmoregulation in Ligia oceanica and Idotea granulosa. J. exp. Biol. 40, $381-392$.

WIEsER, W., 1965. Uber die Häutung von Porcellio scaber LATR. Zool. Anz. (Suppl.) 28, $178-195$.

Wolvekamp, H. P. \& Waterman, T. H., 1960. Respiration. In: Physiology of Crustacea. Ed. by T. H. Waterman. Acad. Press. New York 1, 35-100.

Author's address: Dr. H.-P. Bulnhem

Biologische Anstalt Helgoland (Zentrale)

2 Hamburg 50

Palmaille 9

Federal Republic of Germany 